\title{
Study on the Influence of Emotion Factors in Second Language Acquisition
}

\author{
Yana Liu \\ Xinxiang University, Xinxiang, Henan, China \\ 1654230295@qq.com
}

Keywords: second language acquisition, emotional factors, positive emotion, motivation, anxiety, empathy.

\begin{abstract}
The success of second language acquisition depends on the input of language, the environment of language study, the individual differences of learners and the social and cultural factors of language acquisition, among them, the key factor that affects learner's individual differences is emotion in non-intelligence element. The reason is that emotion factors such as motivation, attitude, interest, self-confidence, self-esteem, anxiety and empathy directly influence the acquisition behavior of second language learners. This paper mainly analyses the influence of emotion factors such as motivation, anxiety and empathy on second language acquisition, and puts forward some relevant countermeasures to fully mobilize positive emotions.
\end{abstract}

\section{Introduction}

The second language acquisition refers to the learning of any other language after the acquisition of mother tongue. The success of second language acquisition depends both on external factors and intrinsic factors. The external factors mainly include social factors, language learning environment, language input and its interaction with language acquisition. The intrinsic factor refers to the learner's individual difference including intelligence and non-intelligence factors. The intelligence factor plays a dominant role in the cultivation of knowledge and ability, and is closely related to the level of language acquisition. But more and more studies have proven that learning motivation, attitude, interest, self-confidence, self-esteem, anxiety, empathy, self-image, the social and cultural environment, personality, fuzzy tolerance and assimilation tendency directly affect the acquisition behavior of second language learners, and have very important influence on second language acquisition, which can promote the development of intelligence and ensure the learner's learning activities achieve actively and ultimately success. Based on this fact, this paper mainly analyzes emotional factors such as motivation, anxiety and empathy's influence on the second language acquisition, and raises some relevant countermeasures to fully mobilize positive emotion, aiming to help the second language teachers and learners to improve their teaching methods and learning styles, and promote language learning as well as improve the efficiency and the level of language learning.

\section{The emotional factors in the second language acquisition process}

Emotional factor refers to the intrinsic ingredient of emotion. Emotion is a kind of function of the human brain, it is the filter and screening of the outside stimulation from the sensory of the cortex and is a kind of psychological state. It is human's attitude and experience to the objective, and whether the objective thing satisfies the individual needs or not determines its emergence. In the process of second language acquisition, emotion is the psychological feeling and emotional experience of learners. Emotional factors can be divided into two categories: one is the individual's emotional factor, another emotional factor refers to the emotional factor between learners and learners, learners and teachers. Motivation, self-esteem, anxiety, empathy and so on all belong to 
the learner's individual emotional factors It means that the interpersonal emotion of learners including empathy, classroom communication, cross-cultural awareness, etc. This part of this paper mainly summarize emotional factors such as motivation, anxiety, empathy which affect the second language acquisition.

\subsection{Motivation}

Motivation is an impetus that could drive the second language acquisition and learning and it is a cognitive and emotional motivation. It is a vital factor which influence the second language acquisition and learning success and motivate learners to make a conscious decision with considerable efforts to achieve the desired learning goals. The second language acquisition and learning is so arduous that to maintain the correct and lasting motivation is the premise of learning a second language. Some people study the second language only on the whim of interest, and will be easily discouraged when they meet difficulties. That's because they are lack of correct motivation.

There are many classifications of learning motivations, the most influential theory is put forward by Gardner and Lambert. They divided the second language acquisition and learning motivation into two categories: integrative motivation and instrumental motivation. The former refers to the learners have a keen interest or genuine interest to the target language community, and they hope to build close relationship with the community and one day can be accepted by the society and become a member of it. Generally speaking, this type of motivation have no direct link to the future and economic interests of the learner's, it is an intrinsic motivation. The latter motivation just for a particular purpose, such as to pass through a certain examination, obtaining a scholarship, getting a job and so on. They regard the second language as a tool, which is related to the future of the individual and comes from the external motivation. The learners who hold the integrative motivation have a definite goal to study the second language and have adequate preparation to fight against various difficulties. They have positive learning attitude and self-consciousness, so the ultimate effect is effective and the motivation of learning is also great. However, the people who are instrumental motivation learners lack of enthusiasm and initiative, their learning enthusiasm is often temporary, once the tool is not needed anymore or they have got short-term success, they often give up learning the second language. At present, the second language teaching environment, Chinese and western language and cultural differences, learning methods and other factors have exert great influence on language learning, most of the second language learners belong to instrumental motivation group. For example, for most college students, their motivation is to pass CET-4, to obtain a CET certificate, because this is linked to diplomas, degree certificate and employment. But this didn't mean that the second language can not be learned well. As long as the purpose of learning is targeted with perseverance attitude, the motivation is correct and to eliminate fluky psychology, we can master the second language. Therefore, it is very important for learners to cultivate correct learning motivation.

\subsection{Anxiety}

Anxiety is a kind of abnormal emotion, which is manifested as anxiety, uneasy and worried. Linguists Car-roll, Gardner and Naiman use "anxiety" to describe the emotional experience and anxiety such as nervousness, worry and scare that people often have in learning and using the second language. According to Ellis's Research, there have at least three different kinds of anxiety states, namely temperament anxiety, one-time anxiety and situation anxiety. Temperament anxiety is a long-term and related with the learner's personality anxiety. One-time anxiety refers to the anxiety at a certain time, and situation anxiety refers to anxiety generated under specific topic and situation. Scovel divides anxiety emotions into two categories: facilitative anxiety and debilitative anxiety. In the second language acquisition process, anxiety can promote learners ' acquisition of second language. Especially when it could stimulate learners to overcome difficulties, challenge new learning tasks and strive to overcome anxiety, it's role is positive. But when it causes students to evade anxiety by avoiding learning tasks, their role is negative. For example, in the second language listening class, the more uneasy the learners are, the less language content they get. In the second spoken language class, the more worried the learners are, the less desire to communicate 
with his classmates and teachers, and they even give up answering the teacher's question. Anxiety can severely affect the number of language input and the quantity and quality of language output for second language learners.

Moderate anxiety is beneficial for second language acquisition. It can give people a certain sense of urgency and effectively stimulate the spirit of uprising, confront challenges bravely, and thus promote learning. If a second language learner has no anxiety, he will be in a relaxed state for a long time. So the learner will have no sense of urgency or not to work hard. However, over-anxiety will lead the learners always be in a intense state, their own thinking and memory ability will drop down, which seriously affecting the language input and output effect. In turn, the over-anxiety will cause a vicious circle of language learning. Therefore, learners should overcome excessive anxiety--debilitative anxiety, and make full use of moderate anxiety---facilitative anxiety.

\subsection{Empathy}

Empathy is the mutual understanding of the thoughts and feelings, emotions and viewpoints, and is an important factor in the successful acquisition of the second language. Empathy, is to look at the problem from the perspective of others (Arnold \& Brown, 2000) and resonate with other people's thoughts, opinions and emotions (Richards J C et al,2000;Stern,1983). The movement of empathy involves two aspects, one is to understand their own emotions, the other is to identify the emotions of others. With the help of empathy, people are no longer confined to the existing mode of thinking, and can comprehensively assess themselves and the people and things around them objectively and fairly. Empathy is one of the most important factors in living harmony with other people, and language is an important way to advance empathy development. In the second language acquisition process, for example in class, when learners want to express ideas, they can not make right judgment because of language barriers, so the emergence of errors is inevitable. In such case, teachers sometimes forget their own experience of learning of the second language, they deal the learner's error with harsh methods, so that the class falls into emotional crisis situation, which exacerbated the role of inhibition, resulting in severely learning effect for the second language learners.

\section{The countermeasures of mobilizing positive emotion in the process of second language acquisition}

As can be seen in the above overview of the emotional factors hold by the second language learners in the learning process, these psychological ingredients are indeed closely linked with the second language learning process and the results, which are of great significance in the second language acquisition featured with the interactive communication characteristics. Therefore, learners should consciously use various methods to mobilize positive emotion to participate in the second language learning, give full play to the active emotion of intelligence, power, regulating, infection and empathy function, to improve the acquisition of second language quality and level.

\subsection{Develop positive expectations for learners}

According to expectation theory, not only personal expectation but also others ' expectation for learners will affect learners ' motivation. In the process of second language acquisition, the teachers ' expectation for students directly influences the students ' motivation and quality of learning. By changing the teachers ' expectation to students, it can effectively promote the students ' level of acquisition of second language and cultivate the students ' learning attitude to study actively.

\subsection{Proper self-attribution}

In the second language acquisition process, the learner who attributes their success or failure to they endeavour or not will have self-confidence be improved and strengthened in learning language. The reason is that efforts can change the factors that are depended on themselves. The so-called "one's ability mostly depends on themselves", is to inform people to understand the importance of efforts for success. The enhancement of self-confidence could help learners overcome excessive 
anxiety--facilitative anxiety, and improve the number and quality of language input of second language learners.

\subsection{Empathy teaching for learners}

Empathy teaching helps to improve students ' understanding and emotion, while the key of empathy teaching is teachers. Teachers should possess the sense of familiarity, harmony, understanding, trust and responsibility. Empathy teaching requires teachers to use their true feelings to infect and motivate students, and thus perform the function of empathy. In the second language acquisition process, the appropriate use of empathy strategy, the creation of relaxed and pleasant language environment and the elimination of students ' restraint, tension, fear of feeling can give learners strong desire to explore knowledge under an actively learning atmosphere and effectively grasp second language.

\section{Conclusion}

The successful learning of the second language not only need higher intelligence, but also have good non-intelligence factor----emotion factor. Therefore, in the second language teaching process, we should create favourable conditions, focusing on the cultivation of emotional factors, changing the teachers ' expectation to students, stimulating learners ' motivation and carrying out proper selfattribution to enhance self-confidence and overcome excessive anxiety. What's more, to implement empathy teaching for learners and create a good atmosphere for language learning, and ensure students learn language in a relaxed and pleasant environment.

\section{References}

[1] Jane Arnold. Affect in Language Learning [M]. Cambridge: Cambridge University Press, 2000.

[2]R .C.Gardner \& W. Lambert“.Motivation Variables inSecond Language Acquisition”in Canadian Journal of Psychol-ogy [J]. 1989(13): 226- 227.

[3]Wang Huiping, Ou Xiaoxia. The Influence of Non-intelligence Factors on Second Language Acquisition [J]. Shandong Foreign Language Teaching, 1996(1). 